\title{
Friend-Invitation Promotion Scheme Used in Electric Carsharing: Empirical Analysis and Policy Implications
}

\author{
Jiemin Xie, ${ }^{1}$ Tuo Sun $\mathbb{D D}^{2}$, and Shuangjian Yang ${ }^{3}$ \\ ${ }^{1}$ Department of Civil Engineering, The University of Hong Kong, Pok Fu Lam, Hong Kong, China \\ ${ }^{2}$ Key Laboratory of Road and Traffic Engineering of the Ministry of Education, Tongji University, Shanghai 201804, China \\ ${ }^{3}$ Ping An International Smart City Technology Co., Ltd., Shenzhen, China
}

Correspondence should be addressed to Tuo Sun; suntuo@tongji.edu.cn

Received 29 May 2021; Accepted 3 July 2021; Published 9 July 2021

Academic Editor: Qi-zhou Hu

Copyright (C) 2021 Jiemin Xie et al. This is an open access article distributed under the Creative Commons Attribution License, which permits unrestricted use, distribution, and reproduction in any medium, provided the original work is properly cited.

\begin{abstract}
The combination of electric vehicle (EV) and carsharing is expected to provide social and environmental benefits, like encouraging sustainable travel behaviors (reducing car ownership and vehicle kilometres of travel) and improving the accessibility and flexibility of urban transport. Thus, electric carsharing is encouraged to be adopted for daily trips, and the operators propose the friend-invitation promotion scheme for the membership expansion. This study explores the effectiveness of this scheme and the characteristics of the scheme participants and their invited friends (e.g., age, friend-invitation pattern, and EV rental pattern). The analysis found that $28.4 \%$ of these invited friends would make at least one EV rental after registration, whereas $30.4 \%$ of the other members who registered in the same period would do so, indicating that these invited friends were less active. Therefore, suggestions are given based on the EV rental pattern of these invited friends (preferring a longer journey using a smaller but cheaper EV) to enhance the effectiveness of the friend-invitation promotion scheme.
\end{abstract}

\section{Introduction}

The ownership of private car keeps increasing [1], and China has been estimated to have 530-623 million vehicles by 2050 [2]. A private car is appealing because it offers doorto-door service with the needed privacy. Furthermore, COVID-19 has been found to change travel behaviors. Zhang et al. [3] suggested that the adult metro users in Hong Kong reduced more than $40 \%$ of their metro trips during the first three months of 2020. It is questionable whether the public transportation usage would be back to the level before the COVID-19. Because of the fear of infection, people more or less tend to avoid a crowded environment and it is possible that the public transportation users will have a stronger desire to buy a car than before. Zhang and Lee [4] conducted a questionnaire survey to study the possible post-COVID-19 travel behavior in China and revealed that the decrease in the public transportation travels could reach $20.5 \%$, whereas that in the private car travels was $6.4 \%$.
Carsharing service provides another option to people, which may help to control the ever-increasing car ownership $[5,6]$ because it can offer the needed privacy and flexibility which are similar to those provided by driving a private car. Meanwhile, the fixed cost of using a carsharing service is much lower than that of driving a private car which requires a large amount of money for purchasing a car and car parking space [7]. Also, a vehicle used in carsharing would not be shared by as many people as those served by a bus or a metro, and carsharing companies promise to disinfect their vehicles as frequently as possible. This may help to alleviate the fear of infection during a journey. However, some have argued that carsharing service would also have influence on public transportation usage [7-10], as it may induce public transportation users to drive, which can result in the increase of carbon emission. Electric carsharing can balance this conflict because electric vehicles (EVs) do not produce carbon emissions on the road and still provide satisfactory services to people [11-13]. It may be the first step to persuade people to give up owning a car. Without owning a car, 
people can make a wiser decision on mode choices based on their travel purposes and increase the possibility of the mixture of transport modes and more environmentally friendly travel behaviors [6].

Electric carsharing companies provide EV rental services and encourage their customers to register to be a member. Membership is wildly used in the transport area (such as air travel) and is thought to play an important role in choice behavior [14]. One of the promotion schemes to increase members is the friend-invitation promotion scheme. A member can invite his/her friend to register, and once the friend becomes a new member, the member and his/her friend would enjoy a reward, such as a rental discount. Although the friend-invitation promotion scheme is widely adopted in the carsharing market, this scheme has not been studied in the context of carsharing yet, to the best of the author's knowledge. Hence, this study tries to bridge this research gap. The main contributions of this study are as follows:

(1) To explore the characteristics of the members who invite friends to register and who accept the friend invitation to register

(2) To analyze the electric carsharing pattern of the members who are invited to register

(3) To provide policy implications for the friend-invitation promotion scheme to enhance the sustainable development of electric carsharing

The remainder of this paper is organized as follows. In Section 2, a review of literature on electric carsharing and its sustainable development is provided. Section 3 describes the data that were provided by the EVCARD (the first electric carsharing company in China), the methods used for data analysis, and the results and a discussion of the analysis. Policy implications and suggestions for electric carsharing companies are given in Section 4, and the conclusion is given in Section 5.

\section{Literature Review}

Carsharing, which provides car access to people for a certain period, can date back to the 1940s, and the relative commercial activities can be traced back to the mid-1990s [15]. However, as the price of the private car became much cheaper, carsharing turned to be less attractive until the rising fuel prices and heavy road congestion have drawn the public's attention back to carsharing [8]. In recent years, shared mobility becomes a hot topic in transport development, and so does electrification $[12,16,17]$. Electric carsharing, a form of carsharing which rents EVs to people, combines these two items and is expected to inherit their positive impacts on sustainable transport development, including guiding the public to form a sustainable travel behavior [6], improving the accessibility and flexibility of the urban transport [12], reducing car ownership [5], vehicle kilometres of travel [9], traffic congestion [18], parking land use [18], and greenhouse gas emissions [11]. Hence, electric carsharing attracts many researchers. Liao and Correia [12] reviewed the studies of electric carsharing, and we refer interested readers to this review for further details.

In China, the first electric carsharing company, EVCARD, was launched in 2013 in Shanghai, followed by other electric carsharing companies like Yikazuche and Weigongjiao. Ministry of Transport in China posed the guidance for the sustainable development of vehicle rentals in 2017 (Guidance for the sustainable development of vehicle rentals: http://www.gov.cn/xinwen/2017-08/08/ content_5216567.htm (accessed on May 20, 2021)). In this guidance, the environmental and social benefits of vehicle rentals are highlighted, and carsharing, especially electric carsharing, is expected to provide a new approach to solve the existing problems of urban mobility. Hence, the Chinese government supports the development of electric carsharing and requires that its development should be sustainable.

To ensure sustainability, electric carsharing companies face different challenges during the planning, management, and operation, including the demand management [10, 19], efficiency of recharging [20], the station location choice $[9,18]$, the safety management [21], etc. Many pilot studies have been performed to solve these challenges. For example, Wang and Yan [10] conducted a questionnaire survey in Shanghai and found that people's willingness to adopt electric carsharing was higher if the people were young, male, and public transportation users with middle-level income. Hence, they suggested that electric carsharing companies should target these people and pay attention to reduce the walking time to an electric carsharing station and the waiting time for assigning an available EV. Hu et al. [18] analyzed the number of customer requests and turnover rates at stations using the rental records of the EVCARD and recommended that new stations should be built in the areas with the low accessibility of metro services and the local authorities should consider the geographical balance of stations to ensure the spatial equality. Chen et al. [9] studied the station usage imbalance based on the EVCARD data. They argued that electric carsharing could not compete with the metro during peak hours because of the high reliability of the metro. During the off-peak peak period, electric carsharing and the metro actually worked together to help people complete their trips. However, electric carsharing competed with the bus. Hence, Chen et al. [9] advised that stations of electric carsharing could be located near metro stations but not bus stops. Lan et al. [21] distributed online questionnaires to the EVCARD' customers to study the impact of the perceived risks of customers in electric carsharing, like fears of opportunistic behaviors, information asymmetry, and service uncertainty. They found that a high level of the perceived risks would encourage antisharing behaviors, and thus they suggested mitigating these risks to achieve a win-win situation. Tao et al. [13] designed a statedpreference survey in Nanjing to investigate carsharing choices. They observed that young people or people with higher education were more likely to adopt carsharing, and thus suggested that carsharing stations could be built in the area with more educated people, such as universities.

Moreover, with the quick development of Internet services, customers generally book carsharing services via 
smartphone apps. Some Internet-oriented promotion schemes are also adopted by carsharing companies for their sustainable development. For example, the EVCARD uses the friend-invitation promotion scheme, which is considered an efficient and effective method for the user growth of mobile games [22] and social software [23]. The EVCARD allows its members to copy e-links in its app to the Internetbased social software (e.g., QQ and WeChat) to invite their friends to register as a member. The friend-invitation promotion scheme contributed to more than $20 \%$ of the EVCARD's membership increase in the first five months of 2016. However, to the best of our knowledge, this scheme has not been studied in any literature in the context of carsharing. Hence, there are a number of questions waiting for exploring, such as who would be more likely to invite friends to use electric carsharing, who would be more likely to accept the friend invitation to register as an electric carsharing member, and what differences would be between the invited and not-invited new members. This study uses the EV rental records provided by the EVCARD to analyze the above questions and gives policy implications based on the analysis to further enhance the friend-invitation promotion scheme, which can contribute to the sustainable development of electric carsharing.

\section{Data Analysis}

In this section, the data description is given in Section 3.1, while the analysis method and results with discussion are presented in Sections 3.2 and 3.3, respectively.

3.1. Data. The EVCARD was established in Shanghai in 2013 as the first electric carsharing company in China (EVCARD: https://en.wikipedia.org/wiki/EvCard (accessed on May 18, 2021)) and had expanded to 38 other Chinese cities by 2017 [18]. Considering the different needs on the rental duration and the rental period, the EVCARD provides four types of service as follows:

(1) General rental in which the rental duration could be minutes or hours in a day

(2) Overnight rental in which the rental period is from 18:00 to 9:00 in the next day

(3) Short-period rental in which the rental duration is from one day to one month

(4) Long-period rental in which the rental duration is more than one month

Customers need to pay a deposit and register to be members before they can book an EV via the EVCARD smartphone app. Members can get EVs from the nearby rental station. During their journeys, they can go to any rental stations for recharging or vehicle exchange. Also, they can return EVs to any rental stations at any time and pay their bills via the smartphone app at the end of their journeys.

The data provided by the EVCARD was collected in Shanghai. Although Shanghai is equipped with a wellestablished public transportation system, the road congestion problem is more and more serious due to the ever- increasing private car usage, and carsharing is considered as a competitive option to solve the problem. According to the study of Hu et al. [18]; in Shanghai, the EVCARD owned 5,213 EVs and 1,473 stations by the end of 2016, and the most EVCARD members were young men. In addition, college students were considered to be interested in the EVCARD, and the second-highest number of EV rentals was recorded at the station in the Jiading campus of Tongji University.

The data included the basic information of the EVCARD's members who registered with his/her driving license on and before May 2016, the friend-invitation records collected from January 2016 to May 2016, and the EV rental records collected from January 2016 to August 2016. The member basic information includes the recoded member ID, age, and registration time; a friend-invitation record marks a successful friend invitation, consisting of the recoded member IDs of the scheme participant and his/her friend who already registered as a member; and a rental record includes the type of the rental EV, the running mileage, the time to get the rental EV, and the rental duration. The data contains two EV types. The type with five seats (Type 2 including Roewe and Zinoro) requires a higher rental price than the other type with four seats (Type 1 including Chery) (EV types used in EVCARD: https://www. evcard.com/models/ (accessed on May 18, 2021)). The credibility of rental records was checked by a speed-limit rule. The rule was set based on the maximum speed in China $(120 \mathrm{~km} / \mathrm{h})$ (Speed limits by country: https://en.wikipedia. org/wiki/Speed_limits_by_country (accessed on May 17, 2021)) and required that the running mileage should not be larger than the rental duration multiplied by the maximum speed. If a rental record did not follow the rule, this rental record was unrealistic and thus discarded. In total, the data contained 86,806 registered members and their 13,687 friend-invitation records and 319,971 EV rental records.

\subsection{Methods. Some types of members are defined as follows:}

(1) Members who registered as members before January 2016 were considered as the old members

(2) Members who registered as members within the period from January 2016 to May 2016 were considered as the new members

(3) Members who were the new members and registered as members via the friend-invitation promotion scheme were considered as the invited new members

(4) Members who were the new members but registered as members not via the friend-invitation promotion scheme were considered as the not-invited new members

(5) Members who successfully invited at least one friend within the period from January 2016 to May 2016 were considered as the scheme participants

(6) Members who were not only the old members but also the scheme participants were considered as the old scheme participants 
(7) Members who were not only the new members but also the scheme participants were considered as the new scheme participants

The set diagram for these types of members is shown in Figure 1.

Electric carsharing patterns of different member types will be studied, such as activeness ( $\left.x^{\text {Activeness }}\right)$, the number of EV rentals $\left(x^{\text {Rental }}\right)$, running mileage $\left(x^{\text {Mileage }}\right)$, and type of the rented $\mathrm{EV}\left(x^{\text {Type }}\right)$. A member was considered to be active if he/she made at least one EV rental during the first eight months in 2016. The value of $x^{\text {Activeness }}$ was defined as follows:

$$
x^{\text {Activeness }}= \begin{cases}1, & \text { if the member made at least one EV rental, } \\ 0, & \text { otherwise }\end{cases}
$$

The more EV rentals he/she completed, the higher his/ her activeness level would be. Thus, $x^{\text {Rental }}$ was used to describe the activeness level. And, $x^{\text {Type }}$ was defined as follows:

$$
x^{\text {Type }}= \begin{cases}1, & \text { if the rented EV belonged to Type } 1, \\ 2, & \text { otherwise }\end{cases}
$$

The average of $x^{\text {Type }}\left(\bar{x}^{\text {Type }}\right)$ was used to describe the general selection of EV type to rent, while the average of $x^{\text {Mileage }}\left(\bar{x}^{\text {Mileage }}\right)$ was adopted for describing the general travel distance of a trip via a rented EV.

We had performed 25 tests in this analysis. For each test, we assumed that different sample groups were independent and had carefully checked the normality of the variables (including age, number of successful friend invitations, $x^{\text {Rental }}, \bar{x}^{\text {Mileage }}$, and $\left.\bar{x}^{\text {Type }}\right)$. We found that the residuals of these variables did not follow a normal distribution. Hence, we adopted a one-way analysis of variance (ANOVA) on the ranks method [24] and the Mann-Whitney Wilcoxon test [25], which relax the normal distribution assumption. The one-way ANOVA on ranks method was used to check whether the variables of different sample groups originated from the same distribution, and the Mann-Whitney Wilcoxon test was used to compare the difference in variables of two samples. We performed these tests and calculated the relative $95 \%$ confidence intervals (CIs) by using $\mathrm{R}$ software $[26,27]$.

The null hypotheses used in this data analysis and their respective tests are summarized in Table 1.

3.3. Results and Discussion. A general situation will be firstly discussed, and then the analysis of the friend-invitation promotion scheme will be presented.

3.3.1. General Situation. The age distribution was shown in Figure 2. Besides, Figure 2 shows that the age range was from 18 (the minimum driving age in China (List of minimum driving ages-East Asia: https://en.wikipedia.org/wiki/ List_of_minimum_driving_ages\#East_Asia (accessed on May 18, 2021))) to 75 . Because the EVCARD relies on

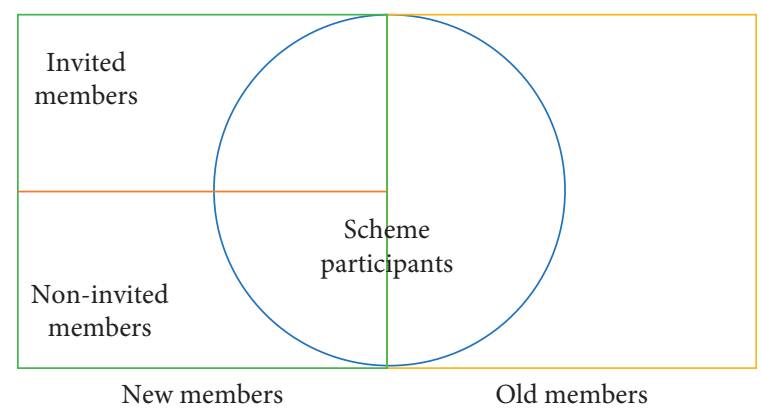

Figure 1: Set diagram for defined types of members.

mobile apps and the elderly people have difficulties using a smart phone [28], it is not surprising to find out that a large proportion of members were young. The mean age of the studied members was about 34.1. This finding is consistent with the previous research, which found that the age of the majority of electric carsharing users was between 30 to 40 [12].

In the studied data, the earliest member registration was recorded in December 2013. Before January 2016, there were 30,139 members. Probably because of the more mature operation of the EVCARD and the rising interest in electric carsharing, a significant increase in membership (around 188.0\%) occurred in the first five months of 2016. The age distribution of the old and new members is presented in Figure 3. As the testing results showed (null hypotheses $1 \&$ 2: $p<0.01^{* *}, 95 \%$ CI: $\left.[-1.00 E 0,-6.07 E-5]\right)$, the age distribution statistically significantly changed, and the new members (34.3 years old on average) were statistically significantly elder than the old members (33.8 years old in average), which indicated that more elder people were attracted by electric carsharing. Besides, about $29.3 \%$ of the studied members had made at least one successful EV rental during the first eight months of 2016.

\subsubsection{Analysis of the Friend-Invitation Promotion Scheme.} Nearly $24.2 \%$ of the encouraging increase in membership was due to the friend-invitation promotion scheme. $6.2 \%$ of the studied members successfully invited friends to register. Specifically, $4.9 \%$ of the old members and $7.0 \%$ of the new members did so, which indicated that the friend-invitation promotion scheme might attract more new members. However, the old scheme participants (about 2.7 successful friend invitations) tended to statistically significantly complete more successful friend invitations than the new scheme participants (about 2.5 successful friend invitations), as the result of testing null hypothesis 3 showed $\left(p<0.01^{* *}, 95 \%\right.$ CI: $[3.81 E-5,6.51 E-5])$. The possible reason could be that the old scheme participants could have a longer participation period because of their earlier registration time and thus make more invitations within the first five months of 2016.

To reduce the influence of registration time, we considered the average number of successful friend invitations in a month which is equal to the total number of successful friend invitations divided by the number of available months. For the old scheme participants, the number of available months was 5 , 
TABLE 1: Null hypotheses were used in the data analysis and their respective tests.

\begin{tabular}{|c|c|}
\hline $\begin{array}{l}\mathrm{S} / \\
\mathrm{N}\end{array}$ & Contents \\
\hline 1 & Ages in the samples of the new and old members originate from the same distribution \\
\hline 2 & The median age of the new members is not greater than that of the old members \\
\hline 3 & $\begin{array}{l}\text { The median number of successful friend invitations of the old scheme participants is not greater than that } \\
\text { of the new scheme participants }\end{array}$ \\
\hline 4 & $\begin{array}{c}\text { The median number of successful friend invitations per month of the new scheme participants is not } \\
\text { greater than that of the old scheme participants }\end{array}$ \\
\hline 5 & $\begin{array}{l}\text { The number of friend invitations in the samples of the new scheme participants who were invited by } \\
\text { friends to register as a member and the other new scheme participants originates from the same } \\
\text { distribution }\end{array}$ \\
\hline 6 & $\begin{array}{l}\text { The median number of friend invitations of the new scheme participants who were invited by friends to } \\
\text { register as a member is not equal to that of the other new scheme participants }\end{array}$ \\
\hline
\end{tabular}

7 The median age of the not-invited new members is not greater than that of the invited new members

The median age of the scheme participants is not less than that of the other members

9
During the first eight months in 2016, activeness in the samples of the old members and the invited new members originate from the same distribution

During the first eight months in 2016, the median activeness of the old members is not equal to that of the invited new members

During the first eight months in 2016, the median activeness of the not-invited new members is not greater than that of the invited new members

During the first eight months in 2016, the median $x^{\text {Rental }}$ of the old active members is not greater than that of the invited new active members

During the first eight months in 2016, the median $x^{\text {Rental }}$ of the invited new active members is not greater than that of the not-invited new active members

The median $x^{\text {Rental }}$ within the period from June 2016 to August 2016 of the invited new active members is not greater than that of the old active members

The median $x^{\text {Rental }}$ within the period from June 2016 to August 2016 of the invited new active members is not greater than that of the not-invited new active members

During the first eight months in 2016, the median $\bar{x}^{\text {Mileage }}$ of the invited new active members is not greater than that of the old active members

During the first eight months in 2016, the median $\bar{x}^{\text {Mileage }}$ of the invited new active members is not greater than that of the not-invited new active members

During the first eight months in 2016, for the invited new active members, $\bar{x}^{\text {Mileage }}$ in the samples of who made successful friend invitations and who did not make successful friend invitations originate from the same distribution

During the first eight months in 2016, for the invited new active members, the median $\bar{x}^{\text {Mileage }}$ of those who made successful friend invitations is not equal to that of those who did not make successful friend invitations

During the first eight months in 2016, the median $\bar{x}^{\text {Type }}$ of the old active members is not greater than that of the invited new active members

During the first eight months in 2016, the median $\bar{x}^{\text {Type }}$ of the not-invited new active members is not greater than that of the invited new active members

During the first eight months in 2016, $\bar{x}^{\text {Type }}$ in the samples of the old active members and not-invited new active members originate from the same distribution

During the first eight months in 2016, the median $\bar{x}^{\text {Type }}$ of the old active members is not equal to that of the not-invited new active members

During the first eight months in 2016, for the invited new active members, $\bar{x}^{\text {Type }}$ in the samples of those who made successful friend invitations and those who did not make successful friend invitations originate from the same distribution

During the first eight months in 2016, for the invited new active members, the median $\bar{x}^{\text {Type }}$ of those who

25 made successful friend invitations is not equal to that of those who did not make successful friend invitations
Tests

One-way ANOVA on ranks

Mann-Whitney Wilcoxon test

Mann-Whitney Wilcoxon test

Mann-Whitney Wilcoxon test

One-way ANOVA on ranks

Mann-Whitney Wilcoxon test

Mann-Whitney Wilcoxon test

Mann-Whitney Wilcoxon test

One-way ANOVA on ranks

Mann-Whitney Wilcoxon test

Mann-Whitney Wilcoxon test

Mann-Whitney Wilcoxon test

Mann-Whitney Wilcoxon test

Mann-Whitney Wilcoxon test

Mann-Whitney Wilcoxon test

Mann-Whitney Wilcoxon test

Mann-Whitney Wilcoxon test

One-way ANOVA on ranks

Mann-Whitney Wilcoxon test

Mann-Whitney Wilcoxon test

Mann-Whitney Wilcoxon test

One-way ANOVA on ranks

Mann-Whitney Wilcoxon test

One-way ANOVA on ranks

Mann-Whitney Wilcoxon test

${ }^{* *}$ and ${ }^{*}$ denote that an estimate is statistically significant at the level of $1 \%$ and $5 \%$, respectively. 


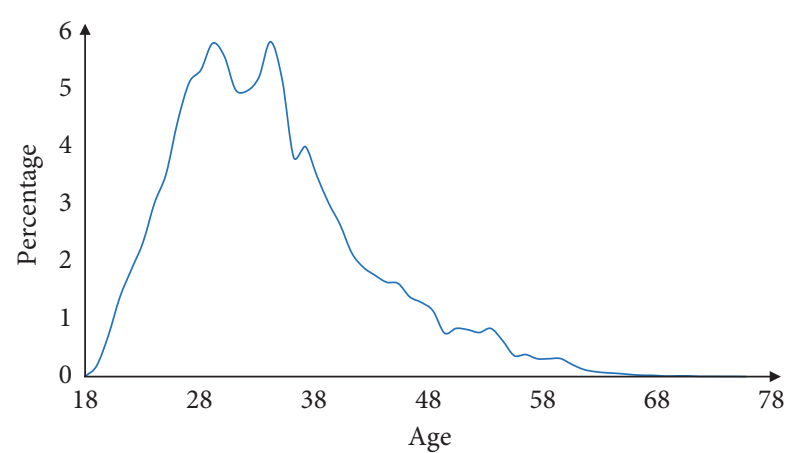

FIgURE 2: Age distribution of the studied members.

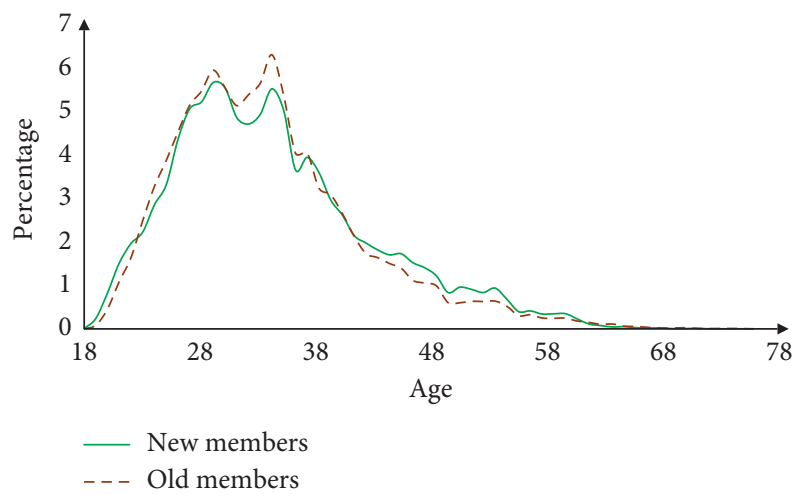

FIgURE 3: Age distributions of the new and old member groups.

and that for the new scheme participants was the number of months after they registered as a member. Averagely, the old scheme participants made 0.5 successful friend invitations per month, whereas the new scheme participants made significantly more successful friend invitations per month (nearly 1.0 successful friend invitations per month, and null hypothesis 4 : $p<0.01^{* *}, 95 \%$ CI: $\left.[-2.67 E-1,-2.00 E-1]\right)$. This result indicated that the new scheme participants might have more passion for this scheme.

Besides, $12.7 \%$ of the invited new members made at least one successful friend invitation. This percentage was higher than those of the old and new members, showing that the invited new members might be more likely to be attracted by the reward of the friend-invitation promotion scheme. But these invited new members seemed to make a similar number of friend invitations as the other new scheme participants (null hypotheses $5 \& 6: p=0.33,95 \%$ CI: $[-2.76 E-5,6.52 E-5])$.

In terms of the age difference, the mean age of the invited new members was 33.2 , less than that of the not-invited new members (mean age $=34.7$ ), and the result of testing null hypothesis $7\left(p<0.01^{* *}, 95 \%\right.$ CI: $\left.[1.00 E 0,1.00 E 0]\right)$ showed that this difference was statistically significant. Moreover, the mean age of the scheme participants (mean age $=31.8$ ) was statistically significantly smaller than that of other members (mean age $=34.3$ ), as the result of testing null hypothesis 8 $\left(p<0.01^{* *}, 95 \%\right.$ CI: $\left.[2.00 E 0,2.00 E 0]\right)$ showed. These results illustrated that younger people were more likely to be interested in the friend-invitation promotion scheme.
Furthermore, we separated the total members into three groups, the old members, the invited new members, and the not-invited new members, and analyzed their electric carsharing patterns, including activeness, number of EV rentals, average running mileage, and a general selection of EV type to rent.

First, the activeness was explored. The member who made the most EV rentals completed $486 \mathrm{EV}$ rentals from March 9 to August 31. Averagely, he/she made 2.7 rentals per day, illustrating that he/she might be quite satisfied with electric carsharing and rely on electric carsharing for daily travel (e.g., commuting). However, as Figure 4 shows, the majority of the studied members did not make any EV rentals during the first eight months of 2016. $28.1 \%$ of the old members were still active, whereas $28.4 \%$ of the invited new members and $30.4 \%$ of the not-invited new members were active.

As the results showed (null hypotheses $9 \& 10: p=0.49$, 95\% CI: $[-4.62 E-5,3.38 E-5]$; and null hypothesis 11 : $p<0.01^{* *}, 95 \%$ CI: [3.40E-5, $\left.4.30 E-05\right]$ ), the activeness of the invited new members seemed to be similar to that of the old members, but statistically significantly lower than that of not-invited new members. The invited new members might be less self-motivated to begin to use electric carsharing because they might just want to do a favour for their friends so that their friends could enjoy the reward.

Second, the old active members (average number of EV rentals $=16.4$ ) tended to make significantly more EV rentals than the invited new active members (average number of EV rentals of the invited new active members $=11.5$, and null hypothesis 12: $p<0.01^{* *}, 95 \%$ CI: [7.04E-05, 1.00E0]), probably because of the difference in the registration time. Besides, the not-invited new active members (average number of EV rentals $=10.5$ ) seemed to make significantly fewer EV rentals than the invited new active members (null hypothesis 13: $p<0.01^{* *}, 95 \% \mathrm{CI}$ : $[-1.00 E 0,-1.00 E 0]$ ). The respective distributions were presented in Figure 5. To reduce the influence of registration time, the number of $\mathrm{EV}$ rentals within the period from June 2016 to August 2016 was considered. All of the active members were registered before this period. The average number of EV rentals within the three-month period of the old active members, the invited new active members, and the not-invited new active members were $6.0,7.5$, and 5.7, respectively. The respective distributions were presented in Figure 6. The tests results supported that the invited new active members made significantly more EV rentals than other active members (null hypothesis 14: $p<0.01^{* *}, 95 \% \mathrm{CI}:[-1.00 E 0,-1.00 E 0]$ and null hypothesis 15: $p<0.01^{* *}, 95 \% \mathrm{CI}$ : $\left.[-1.00 E 0,-1.00 E 0]\right)$. The possible reason could be that the invited new active members had been more or less persuaded and influenced by their friends who averagely made $7.6 \mathrm{EV}$ rentals within the three-month period. In all, the level of the activeness was low, indicating that some problem existed to hinder members' participation. A further research on finding the reasons should be considered.

Third, the average running mileage of the active members was analyzed. The average running mileages of the old active members, the invited new active members, and the not-invited new active members were $24.5 \mathrm{~km}, 29.2 \mathrm{~km}$, and 


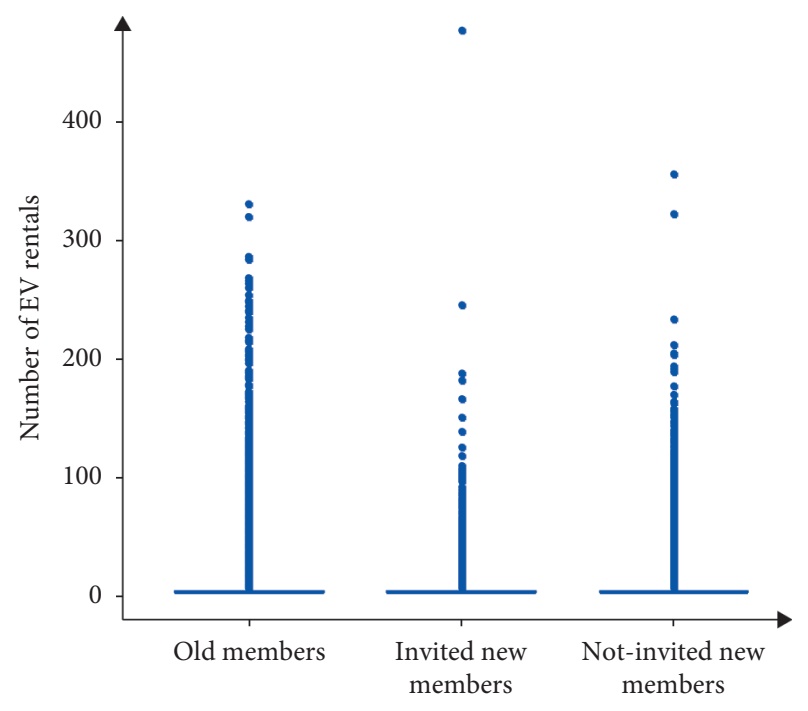

FIgURE 4: Distributions of number of EV rentals of the old members, the invited new members, and the not-invited new members during the first eight months of 2016.

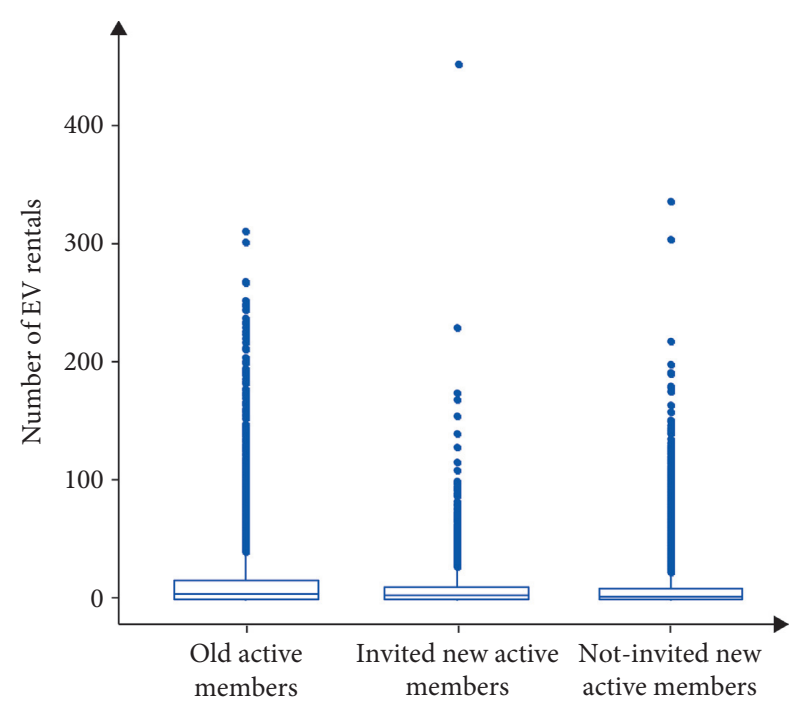

FIGURE 5: Distributions of the number of EV rentals of the old active members, the invited new active members, and the notinvited new active members during the first eight months of 2016.

$27.3 \mathrm{~km}$, respectively, and the results showed that the invited active new members significantly averagely travelled a longer distance than others (null hypothesis 16: $p<0.01^{* *}, 95 \% \mathrm{CI}$ : $[-5.22 E 0,-4.06 E 0]$ and null hypothesis $17: p<0.01^{* *}, 95 \%$ CI: $[-3.14 \mathrm{E} 0,-2.00 \mathrm{E} 0])$. Besides, for the invited new active members, there was no statistically significant difference in terms of trip distance between who made successful friend invitations and who did not (null hypotheses 18 \& 19 : $p=0.20,95 \% \mathrm{CI}:[-1.67 E 0,3.33 E-1])$. The possible reason why the invited new active members preferred longer trips could be that the reward for the registration might encourage them to have a longer trip to spend this monetary reward. It is an interesting issue that will be studied in the future.

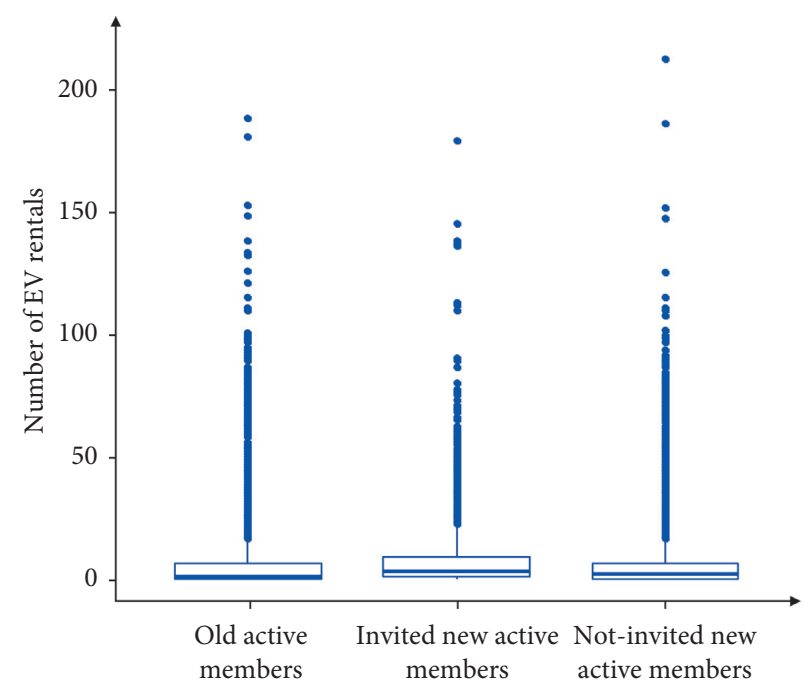

Figure 6: Distributions of the number of EV rentals of the old active members, the invited new active members, and the notinvited new active members within the period from June 2016 to August 2016.

The respective distributions are given in Figure 7. The longest average running mileage was $1,558 \mathrm{~km}$. It was made by the member who only completed one EV rental in the studied period, and the rental duration was four days. The long rental duration might explain why the running mileage was so long. If the majority of trips were assumed to be performed on the urban road, the speed limit was $30-60 \mathrm{~km} /$ h (Speed limits by country: https://en.wikipedia.org/wiki/ Speed_limits_by_country (accessed on May 17, 2021)), and the average speed could be assumed to be $45 \mathrm{~km} / \mathrm{h}$. Hence, the average travel times of the old active members, the invited new active members, and the not-invited new active members were about $32.7 \mathrm{~min}, 38.9 \mathrm{~min}$, and $36.4 \mathrm{~min}$, respectively. These average travel times were similar to that (39 $\mathrm{min}$ ) reported by $\mathrm{Hu}$ et al. [18], who studied the station location choice of electric carsharing using the EVCARD data in 2017.

Fourth, $\bar{x}^{\text {Type }}$ of the active members were studied. The respective distributions of the old active members, the invited new active members, and the not-invited new active members are given in Figure 8 and Table 2. The majority of the active members would consider both EV types, whereas $36.4 \%$ of the active members would only rent one EV Type.

The mean values of $\bar{x}^{\text {Type }}$ of the old active members, the invited new active members, and the not-invited new active members were $1.54,1.51$, and 1.54 , respectively. The result of testing null hypothesis $20\left(p<0.01^{* *}, 95 \%\right.$ CI: [5.32E-5, $1.43 E-2]$ ) seemed to support that there was a significant difference between the old and invited new active members in terms of the selection of EV types, and the not-invited new active members also seemed to significantly prefer a larger and more expensive EV type than the invited new active members (null hypothesis $21: p<0.01^{* *}, 95 \%$ CI: [4.47E - 5, $8.06 E-5]$ ). These differences might be explained by that the invited new active members might be attracted by the monetary reward in the friend-invitation promotion scheme 


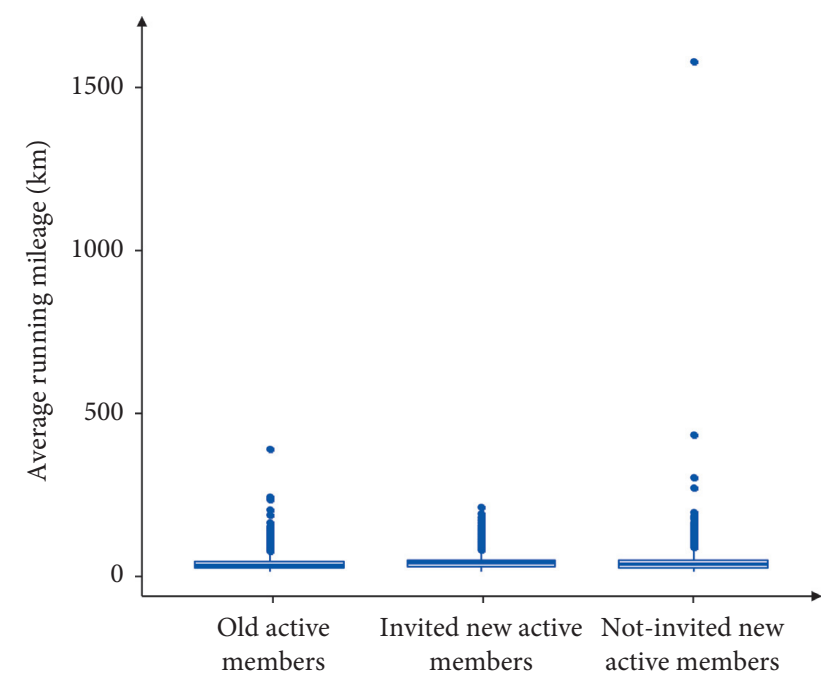

FIGURE 7: Distributions of average running mileage of the old active members, the invited new active members, and the not-invited new active members during the first eight months of 2016.

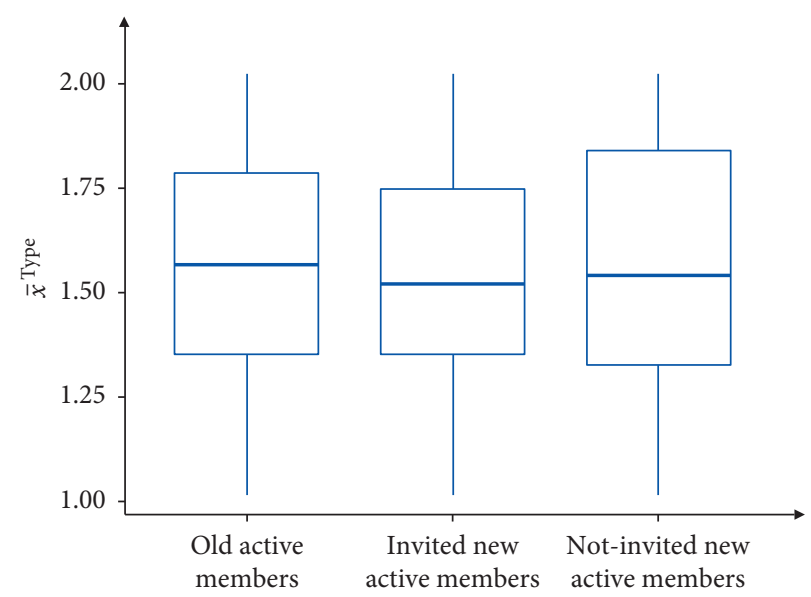

Figure 8: Distributions of $\bar{x}^{\text {Type }}$ of the old active members, the invited new active members, and the not-invited new active members during the first eight months of 2016.

to register and thus, they might be more sensitive to the price and prefer a cheaper EV. Furthermore, the difference between the old and not-invited new active members in terms of the selection of EV types was not statistically significant (null hypotheses 22 \& 23: $p=0.90,95 \%$ CI: [-8.24E-6, $6.10 E-5])$. Also, for the invited new active members, there was no statistically significant difference in terms of the selection of EV types between those who made successful friend invitations and those who did not (null hypotheses 24 \& 25: $p=0.36,95 \%$ CI: $[-4.40 E-3,6.58 E-5])$.

\section{Policy Implications}

As the result given in Section 3.3 and the previous studies on the EVCARD $[13,18]$ show, most members of the EVCARD are young, probably because the elderly people have difficulties operating the e-rental system [28]. Hence, this operation mode seems to exclude elderly people and may cause a potential aging inequality problem. However, this problem may not have a significant impact on elderly people because people would gradually shift from driving to public transportation modes for the most trips as they age [29-31], due to the decreasing ability to drive with increasing age [32]. Therefore, the local governments should pay sufficient financial and administrative supports to public transportation for improving the elderly's mobility while promoting the usage of electric carsharing.

To encourage people to adopt electric carsharing, the friend-invitation promotion scheme is thought to be useful because people generally trust their friends' recommendations more than the advertisement [22], and peer influence often plays an important role on consumption behaviors [33]. The EVCARD adopts the friend-invitation promotion scheme for the market development, and this scheme contributed $24.2 \%$ of the increase in the membership in the first five months of 2016.

However, as the analysis given in Section 3.3.2 shows, the activeness of the invited new members seems to be low. $28.4 \%$ of the invited new members were active, whereas $75.5 \%$ of the scheme participants were active. Besides, the invited new members might be less likely to be active members than the other new members, although the difference between the invited new members and the old members was not significant. As discussed before, some of the invited new members might accept the invitation to register to just help their friends to get rewards, and they were not persuaded to try this new travel mode. However, if they were persuaded and became active members, they seemed to make more EV rentals than other new active members. Thus, the result indicated that the friend's promotion could have a positive impact on the increase in the membership, but the friend invitation to register as a member should be considered as a first step to attract new customers but not the last step. There are some suggestions to enhance the effectiveness of the present friend-invitation promotion scheme.

First, other types of friend-invitation-oriented schemes should be further developed to encourage activeness. For example, if the invited new member completes a milestone, such as the first EV rental, who invited this member could get an extra discount reward. Or a member can invite his/her registered friends to travel during the weekend, and both the member and his/her friends can enjoy a discount if they rent EVs for their own weekend trips.

Second, specific schemes should be designed based on the characteristics of the invited new members to increase the rental rate. For instance, as the analysis in Section 3.3.2 shows, the invited new active members seemed to make longer trips than the other active members. Additionally, they might prefer to book a type $1 \mathrm{EV}$ that has fewer seats with a lower rental price. Therefore, coupons for long-distance trips or renting Type 1 EVs could be distributed to the targeted group.

Third, the operators should pay more effort to encourage members who have a higher potential to participate in the friend-invitation promotion scheme. As the analysis in Section 3.3.2 shows, younger members are more likely to participate in this activity. Besides, $12.7 \%$ of the invited new 
TABle 2: Percentages of members having different EV-type selection patterns.

\begin{tabular}{lccc}
\hline & \multicolumn{3}{c}{ Percentages } \\
& Members who only rented type 1 EV (\%) & Members who only rented type 2 EV (\%) & Other members (\%) \\
\hline Old active members & 16.5 & 17.2 & 66.3 \\
$\begin{array}{l}\text { Invited new active members } \\
\text { Not-invited new active }\end{array}$ & 14.7 & 16.0 & 69.3 \\
members & 18.6 & 21.2 & 60.2 \\
\hline
\end{tabular}

members would make at least one successful friend invitation, whereas $6.2 \%$ of all the studied members would do so. In addition, members who will have more passion for this scheme and make more successful friend invitations should be encouraged to participate. As the analysis in Section 3.3.2 shows, the new members tend to have a higher average number of successful friend invitations in a month if they participate in this scheme. The operators could target the new members and send more relative advertisements via the smartphone app.

Fourth, the operators can distribute some short surveys via their smartphone app to ask the feedback from their customers. For example, after a member makes a friend invitation, the member could be asked for the experience of making a friend invitation and the satisfaction of the reward. Also, when an invited new member does not make any EV rental after the registration, a follow-up survey could be sent to know more details. These small surveys can build good communication between the operators and their customers and help the promotion of electric carsharing.

Fifth, the operators can design some interviews for inactive invited members to understand more about their travel needs and concerns. These interview results can help the operators to develop new strategies to contribute to the sustainable development of electric carsharing.

\section{Conclusion}

This study analyzed the friend-invitation promotion scheme used in electric carsharing based on the data provided by the EVCARD. In the analysis, we had the following main findings:

(1) Most members of the EVCARD were young, and the activeness of the members was low, while about $29.3 \%$ of the members had made at least one EV rental during the studied period

(2) The new members might be more likely to participate in the friend-invitation promotion scheme than the old members, and the new scheme participants might make more successful friend invitations per month than old scheme participants

(3) Compared to the not-invited new members, fewer invited new members were active, but the invited new active members might make more EV rentals and longer EV trips than the not-invited new active members

(4) Compared to the other active members, the invited new active members might prefer a smaller but cheaper EV type
Considering these findings, we provided some suggestions to the operators in Section 4 to further enhance their friend-invitation promotion scheme and improve the sustainable development of electric carsharing.

With the limitations of the data, we cannot further examine the EV rental patterns of the invited active members, such as when and where they are more likely to make an EV rental and what will be the most motivating issue for them to begin the first EV rental. In the future study, we will collect more data via both the stated-preference and revealed-preference surveys and discuss the possible improvements based on the analysis. Furthermore, electric carsharing is now facing many difficulties, and our future study should use the EVCARD platform data and survey data to consider more issues, such as analyzing the travel demand and user types and optimizing station locations and rental prices.

\section{Data Availability}

The data that support the findings of this study were provided by the EVCARD. Restrictions apply to the availability of these data, which were used under license for this study.

\section{Conflicts of Interest}

The authors confirm that there are no potential conflicts of interest.

\section{Acknowledgments}

This work was supported by the National Key Research and Development Program of China (2018YFB1601000) and Shanghai Science and Technology Innovation Action Plan Project (project no. 20DZ1202805). The authors express their sincere gratitude to the EVCARD for the provision of the data used in this research.

\section{References}

[1] J. Firnkorn and M. Müller, "What will be the environmental effects of new free-floating car-sharing systems? The case of car2go in Ulm," Ecological Economics, vol. 70, no. 8, pp. 1519-1528, 2011.

[2] H. Huo and M. Wang, "Modeling future vehicle sales and stock in China," Energy Policy, vol. 43, pp. 17-29, 2012.

[3] N. Zhang, W. Jia, P. Wang et al., "Changes in local travel behaviour before and during the COVID-19 pandemic in Hong Kong," Cities, vol. 112, Article ID 103139, 2021.

[4] J. Zhang and J. Lee, "Interactive effects between travel behaviour and COVID-19: a questionnaire study," 
Transportation Safety and Environment, vol. 3, no. 2, pp. 166-177, 2021.

[5] H. Becker, F. Ciari, and K. W. Axhausen, "Measuring the car ownership impact of free-floating car-sharing-a case study in Basel, Switzerland," Transportation Research Part D: Transport and Environment, vol. 65, pp. 51-62, 2018.

[6] U. Huwer, "Public transport and car-sharing-benefits and effects of combined services," Transport Policy, vol. 11, pp. 77-87, 2004.

[7] S. Le Vine, O. Adamou, and J. Polak, "Predicting new forms of activity/mobility patterns enabled by shared-mobility services through a needs-based stated-response method: case study of grocery shopping," Transport Policy, vol. 32, pp. 60-68, 2014.

[8] H. Becker, F. Ciari, and K. W. Axhausen, "Comparing carsharing schemes in Switzerland: user groups and usage patterns," Transportation Research Part A: Policy and Practice, vol. 97, pp. 17-29, 2017.

[9] X. Chen, J. Cheng, J. Ye, Y. Jin, X. Li, and F. Zhang, "Locating station of one-way carsharing based on spatial demand characteristics," Journal of Advanced Transportation, vol. 2018, Article ID 5493632, 16 pages, 2018.

[10] N. Wang and R. Yan, "Research on consumers' use willingness and opinions of electric vehicle sharing: an empirical study in Shanghai," Sustainability, vol. 8, no. 1, p. 7, 2016.

[11] J. Firnkorn, "Triangulation of two methods measuring the impacts of a free-floating carsharing system in Germany," Transportation Research Part A: Policy and Practice, vol. 46, no. 10 , pp. 1654-1672, 2012.

[12] F. Liao and G. Correia, "Electric carsharing and micromobility: a literature review on their usage pattern, demand, and potential impacts," International Journal of Sustainable Transportation, pp. 1-30, 2020.

[13] Z. Tao, Q. Nie, and W. Zhang, "Research on travel behavior with car sharing under smart city conditions," Journal of Advanced Transportation, vol. 2021, Article ID 8879908, 13 pages, 2021.

[14] M. Seelhorst and Y. Liu, "Latent air travel preferences: understanding the role of frequent flyer programs on itinerary choice," Transportation Research Part A: Policy and Practice, vol. 80, pp. 49-61, 2015.

[15] S. Le Vine, M. Lee-Gosselin, A. Sivakumar, and J. Polak, "A new approach to predict the market and impacts of round-trip and point-to-point carsharing systems: case study of London," Transportation Research Part D: Transport and Environment, vol. 32, pp. 218-229, 2014.

[16] M. Ye, Y. Chen, G. Yang, B. Wang, and Q. Hu, "Mixed logit models for travelers' mode shifting considering bike-sharing," Sustainability, vol. 12, no. 5, p. 2081, 2020.

[17] S. Zhong, X. Li, Y. Jiang, R. Cheng, and Z. Wang, "Identifying the combined effect of shared autonomous vehicles and congestion pricing on regional job accessibility," Journal of Transport and Land Use, vol. 13, no. 1, pp. 273-297, 2020.

[18] S. Hu, P. Chen, H. Lin, C. Xie, and X. Chen, "Promoting carsharing attractiveness and efficiency: an exploratory analysis," Transportation Research Part D: Transport and Environment, vol. 65, pp. 229-243, 2018.

[19] D. Yu, Z. Li, Q. Zhong, Y. Ai, and W. Chen, "Demand management of station-based car sharing system based on deep learning forecasting," Journal of Advanced Transportation, vol. 2020, Article ID 8935857, 15 pages, 2020.

[20] R. R. Desai, R. B. Chen, and W. Armington, "A pattern analysis of daily electric vehicle charging profiles: operational efficiency and environmental impacts," Journal of Advanced Transportation, vol. 2018, Article ID 6930932, 15 pages, 2018.
[21] J. Lan, D. Mangalagiu, Y. Ma, T. F. Thornton, and D. Zhu, "Modelling consumption behaviour changes in a B2C electric vehicle-sharing system: a perceived systemic risk perspective," Climatic Change, vol. 160, pp. 655-669, 2020.

[22] J. Jeong and S. Moon, "Invite your friends and get rewards: dynamics of incentivized friend invitation in kakaotalk mobile games," in Proceedings of the 2nd ACM Conference on Online Social Networks, pp. 151-160, Association for Computing Machinery, Dublin, Ireland, 2014.

[23] Y. Ulusu, "Determinant factors of time spent on Facebook: brand community engagement and usage types," Journal of Yaşar University, vol. 5, no. 18, pp. 2949-2957, 2010.

[24] W. H. Kruskal and W. A. Wallis, "Use of ranks in one-criterion variance analysis," Journal of the American Statistical Association, vol. 47, no. 260, pp. 583-621, 1952.

[25] H. B. Mann and D. R. Whitney, "On a test of whether one of two random variables is stochastically larger than the other," Annals of Mathematical Statistics, vol. 18, no. 1, pp. 50-60, 1947.

[26] A. Kassambara, Practical Statistics in R II-Comparing Groups: Numerical Variables, Datanovia, Sydney, Australia, 2019.

[27] R Core Team, R: A Language and Environment for Statistical Computing, R Foundation for Statistical Computing, Vienna, Austria, 2018.

[28] N. Navabi, F. Ghaffari, and Z. Jannat-Alipoor, "Older adults' attitudes and barriers toward the use of mobile phones," Clinical Interventions in Aging, vol. 11, pp. 1371-1378, 2016.

[29] D. Banister and A. Bowling, "Quality of life for the elderly: the transport dimension," Transport Policy, vol. 11, no. 2, pp. 105-115, 2004.

[30] N. Havet, C. Bayart, and P. Bonnel, "Why do gender differences in daily mobility behaviours persist among workers?" Transportation Research Part A: Policy and Practice, vol. 145, pp. 34-48, 2021.

[31] F. Su and M. G. H. Bell, "Transport for older people: characteristics and solutions," Research in Transportation Economics, vol. 25, no. 1, pp. 46-55, 2009.

[32] E. Douissembekov, C. Gabaude, J. Rogé, J. Navarro, and G. A. Michael, "Parking and manoeuvring among older drivers: a survey investigating special needs and difficulties," Transportation Research Part F: Traffic Psychology and Behaviour, vol. 26, pp. 238-245, 2014.

[33] S. Gulati, "Impact of peer pressure on buying behaviour," International Journal of Research-Granthaalayah, vol. 5, no. 6, pp. 280-291, 2017. 